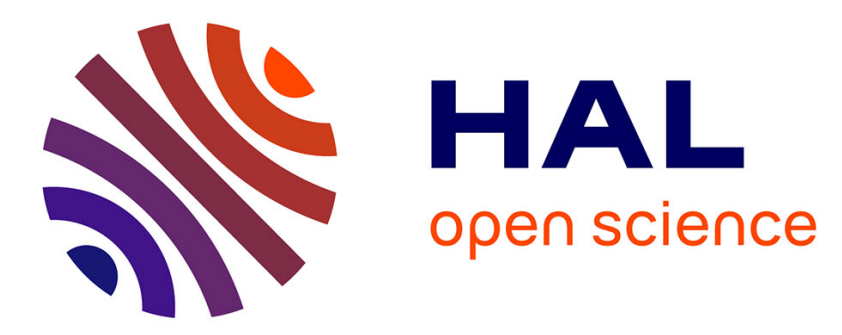

\title{
Experimental investigation on the concentration and voltage effects on the characteristics of deposited magnesium-lanthanum powder
}

M Sahli, K Chetehouna, F Faubert, C Bariki, Nicolas Gascoin, N Bellel

\section{- To cite this version:}

M Sahli, K Chetehouna, F Faubert, C Bariki, Nicolas Gascoin, et al.. Experimental investigation on the concentration and voltage effects on the characteristics of deposited magnesium-lanthanum powder. Applied Geophysics, 2015, 10.1007/s00339-015-9099-y . hal-01253270

\section{HAL Id: hal-01253270 \\ https://hal.science/hal-01253270}

Submitted on 9 Jan 2016

HAL is a multi-disciplinary open access archive for the deposit and dissemination of scientific research documents, whether they are published or not. The documents may come from teaching and research institutions in France or abroad, or from public or private research centers.
L'archive ouverte pluridisciplinaire HAL, est destinée au dépôt et à la diffusion de documents scientifiques de niveau recherche, publiés ou non, émanant des établissements d'enseignement et de recherche français ou étrangers, des laboratoires publics ou privés. 


\title{
Experimental investigation on the concentration and voltage effects on the characteristics of deposited magnesium-lanthanum powder
}

\author{
M. Sahli', K. Chetehouna,", F. Faubert ${ }^{3}$, C. Bariki ${ }^{2}$, N. Gascoin ${ }^{2}$, N. Bellel ${ }^{1}$ \\ ${ }^{1}$ Laboratoire de Physique Energétique, Université de Constantine 1, Algeria \\ ${ }^{2}$ INSA-CVL, Univ. Orléans, PRISME, EA 4229, F-18020, Bourges, France \\ ${ }^{3}$ Univ. Orléans, GREMI, UMR 7343, F-18020, Bourges, France
}

\begin{abstract}
*Address correspondence to Khaled CHETEHOUNA, INSA Centre Val de Loire - Campus de Bourges, Laboratoire PRISME UPRES EA 4229, 88, Boulevard Lahitolle, CS 60013, 18022 Bourges Cedex, France.

E-mail: khaled.chetehouna@insa-cvl.fr
\end{abstract}

Phone: +33248484065

\section{Highlights}

- We synthetize Mg-La powders by means of an electrodeposition process.

- We characterize Mg-La powders using EDS, SEM, XRD and FTIR techniques.

- EDS analyses indicate the presence of three elements (Mg, La and O).

- The two phases, $\mathrm{Mg}(\mathrm{OH})_{2}$ and $\mathrm{La}(\mathrm{OH})_{3}$ are identified in specimens.

- Concentration and voltage effects are investigated using a design of experiments. 


\section{Abstract}

In this paper, magnesium-lanthanum powders were synthesized by an electrodeposition technique using an aqueous solution, based on magnesium chloride hexahydrate and lanthanum nitrate for different values of voltage and La weight percentage. A copper cathode plate and a tungsten thread anode were used for the preparation of the Mg-La layers. The asdeposited powders were characterized by energy dispersive spectroscopy (EDS) to determine the chemical composition, scanning electron microscope (SEM) to describe the morphology, X-ray diffraction (XRD) and Fourier transform infrared (FTIR) spectra in order to define the chemical structure. EDS analyses indicate the presence of three elements ( $\mathrm{Mg}, \mathrm{La}$ and $\mathrm{O}$ ) in the different deposited layers and the major one is $\mathrm{O}$ (51 to 74.2 at.\%). The two other elements, Mg and La, are respectively ranked 2 and 3 in the different powders. Morphological description reveals the formation of heterogeneous chemical structures on the surfaces of specimens. They are characterized by aggregates with different sizes. The dark aggregates are associated to magnesium and the bright ones are attributed to lanthanum. X-ray results showed the existence of two distinct phases in the obtained deposits which are magnesium hydroxide $\left(\mathrm{Mg}(\mathrm{OH})_{2}\right)$ and lanthanum hydroxide $\left(\mathrm{La}(\mathrm{OH})_{3}\right)$. FTIR analyses confirm the presence of the two phases identified in XRD diffractograms and they can be exhibited by clear peaks. In the studied ranges of voltage and La weight percentage, their peak transmittances have non-monotonic behaviors. A design of experiments was used to determine the influence of these two processing parameters and their interaction on the products formation. The parameters effects were ranked as follow: the first was the voltage then the interaction between the two parameters and finally the La content.

Keywords: Chemical synthesis, Electrodeposition, Mg-La powders, Voltage effect, Concentration effect, Design of experiments. 


\section{Introduction}

Since the last decades, magnesium $(\mathrm{Mg})$ is attracting renewed interest. It is a potential candidate for hydrogen storage, as evidenced by numerous studies and publications on this topic [1-5]. Indeed, it is characterized by several advantages. Being a light element allows $\mathrm{Mg}$ to have the highest weight capacity $7.6 \%$ [6]. In addition, it is characterized by various properties for instance a low density, a low cost [7], a very good malleability and ductility, a high strength/weight ratio and an environmentally friendly nature [8]. The use of magnesium is found also limited due to its high chemical reactivity and electronegative potential of -2.34 $\mathrm{V}$ [9]. Given its poor mechanical properties and low corrosion resistance, magnesium cannot be used in pure form as structural material [10]. Hence the need to combine it with other elements in order to optimize these two fundamental characteristics. In fact, adding rare earth (RE) elements as lanthanum, element retained in this work, improve the corrosion resistance, the creep and shear strengths as well as the hydrogen storage capacity [11-13]. Magnesium alloys have been therefore widely used for structural compounds for several decades, particularly in aircraft and automobile industries [14, 15].

At present, different technologies are utilized to prepare Mg based alloy, including thermal spraying [16], diffusion [17], laser cladding [18], CVD (Chemical Vapor Deposition) [19], etc. Besides these methods, metal alloys electrodeposition in aqueous ionic liquids are receiving increased interest [20-23]. The thickness and quality of the deposited layer can be controlled or optimized by processing parameters, such as electroplating time, voltage of electrodeposition or electrolyte composition, etc. At the same time, it is the most economical method for preparing Mg-RE alloys and could be easily implemented on a large scale as well as it could be employed over a large temperature range.

The aim of the work presented in this paper is to study the characteristics of the magnesium-lanthanum layers dedicated to the hydrogen storage applications. These layers are 
elaborated using electrodeposition technique by varying the voltage and the amount of lanthanum in the initial chemical solution. The effects of these two processing parameters on the products formation are investigated through a design of experiments. This paper is organized as follows: section 2 is devoted to the description of samples preparation and characterization devices as well as design of experiments; section 3 examines the results obtained monitoring with discussions based to the ones found in literature. In the end, conclusions are drawn with some indicators to future analyzes.

\section{Materials and methods}

\subsection{Chemicals and specimens preparation}

Different masses of $\mathrm{MgCl}_{2} \cdot 6 \mathrm{H}_{2} \mathrm{O}$ (magnesium chloride hexahydrate) and $\mathrm{La}\left(\mathrm{NO}_{3}\right)_{3} \cdot 6 \mathrm{H}_{2} \mathrm{O}$ (lanthanum nitrate hexahydrate) were dissolved in $34 \mathrm{~mL}$ of ultra-pure water, at ambient temperature $\left(23^{\circ} \mathrm{C}\right)$. Electrodeposition experiments were carried out in a cylindrical electrolysis chamber of an internal volume of $36.64 \mathrm{~mL}$. The inner dimensions of the Plexiglas vessel are $1.8 \mathrm{~cm}$ radius and $3.6 \mathrm{~cm}$ height. A copper cathode plate and a tungsten thread anode, with a $2.2 \mathrm{~cm}$ gap, connected to a conventional potentiometric power source, were used to ensure the deposition of Mg-La powders. Chemicals were purchased from Merck Group and purified water was provided by Medica Lab Elga deionizer system.

The concentration effect was performed by varying the concentration of La from 20 to 60 wt.\% with a step of 20 wt.\%. The different samples were prepared under three different voltage values: 6, 8 and $10 \mathrm{~V}$. The deposition experiments were performed at ambient temperature. The obtained deposits were scraped from the copper cathode plate, dried for $1 \mathrm{~h}$ at $110{ }^{\circ} \mathrm{C}$, milled manually in a marble mortar and subjected to further analyses. Figure 1 shows a photograph and a schematic overview of the described experimental setup. 


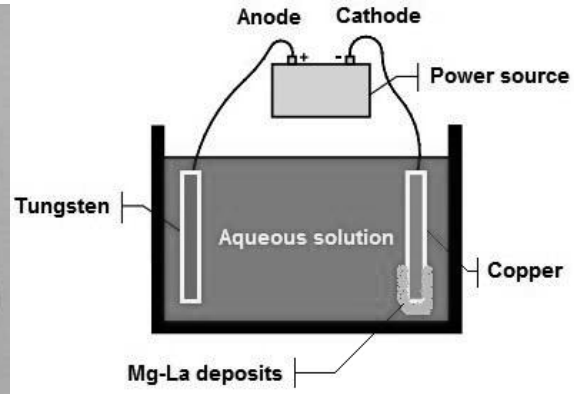

Figure 1 - Picture and schematic overview of electrodeposition experimental setup.

\subsection{Characterization devices}

The morphology and chemical composition of the obtained deposits were investigated by a scanning electron microscope (SEM, LEO $1455 \mathrm{VP}$, acceleration voltage of $20 \mathrm{kV}$ ) at a working distance of $15 \mathrm{~mm}$ equipped with an X-ray energy dispersive spectrometer (EDS, Inca X-sight, Oxford Instrument). The phase identification of the alloys were determined by means of X-ray diffractometer (XRD, Philips $\mathrm{X}^{\prime}$ PERT) using $\mathrm{Cu} \mathrm{K} \alpha$ radiation source $(\lambda=1.54 \AA, 40 \mathrm{kV}, 30 \mathrm{~mA})$ at room temperature. The scanning rate of $0.02 \% \mathrm{~s}$ within the $2 \theta$ range going from $10^{\circ}$ to $80^{\circ}$ was used in order to increase counting statistics and to improve the signal/noise ratio. Fourier transform infrared (FTIR) spectroscopy of the powder samples was carried out with a Nicolet 380 FT-IR spectrometer using the ATR technique. All spectra were collected with the resolution of $4 \mathrm{~cm}^{-1}$ in the range of $4000-500 \mathrm{~cm}^{-1}$.

\subsection{Design of experiments}

Design of experiments, referred to as DOE, is a systematic approach to understanding how parameters affect response variables. DOE is considered one of the most important methodologies for researchers handling experiments in practical applications [24-26] because it provides an organized approach, with which it is possible to address both simple and tricky experimental problems. Thus, by means of DOE, one obtains more useful and more precise information about the studied system, because the joint influence of factors is assessed, which 
will allow to decide what the next experimental step ought to be. Table 1 represents a threelevel design of experiments proposed to determine the influence of the two parameters (La concentration and electrodepositing voltage) on the products formation.

\begin{tabular}{lll}
\hline Level of parameter & Concentration of La [wt. \%] & Voltage [V] \\
\hline+1 & 60 & 10 \\
0 & 40 & 8 \\
-1 & 20 & 6 \\
\hline
\end{tabular}

Table 1 - Levels and parameters of the design of experiments.

\section{Results and discussion}

\subsection{EDS analyses of the as-deposited layers}

The EDS results presented in Table 2 are calculated as the average of three measurements on three different areas, performed using spot mode, in order to obtain the elemental atomic compositions of the different powders. These results clearly show the presence of oxygen, magnesium and lanthanum originating from the used electrolyte. As we can see from this Table, all specimens are characterized by high contents of oxygen (51 to 74.2 at.\%). Except for La weight percentage of $20 \%$ at $6 \mathrm{~V}$, the atomic percentages of $\mathrm{Mg}$ are always higher than those of La. These atomic percentages vary from 12 to $30.6 \%$ for magnesium and from 5.4 to $24 \%$ for lanthanum. For most of EDS analyses, it can be seen that the atomic percentages of $\mathrm{O}, \mathrm{Mg}$ and La have a non-monotonic behavior with the increase of voltage and La weight percentage. This can be explained by the interaction between the voltage (which presents the driving force of the reaction) and the electrolyte composition effects in the electrolysis process. 
Element

\section{Atomic percentage [\%]}

\begin{tabular}{lll}
\hline La 20 wt. $\%$ & La 40 wt. \% 60 wt.\%
\end{tabular}

\section{Voltage of $6 \mathrm{~V}$}

Oxygen

$69.2 \pm 4.2$

$74.2 \pm 4.6$

$51.0 \pm 5.6$

Magnesium

$12.0 \pm 1.3$

$15.3 \pm 1.4$

$25.0 \pm 4.4$

Lanthanum

$18.8 \pm 3.9$

$10.5 \pm 2.1$

$24.0 \pm 3.7$

\section{Voltage of $8 \mathrm{~V}$}

Oxygen

Magnesium

Lanthanum

\section{Voltage of $10 \mathrm{~V}$}

Oxygen

Magnesium

Lanthanum
$57.7 \pm 3.0$

$30.6 \pm 5.6$

$11.7 \pm 4.3$
$62.6 \pm 4.2$

$69.4 \pm 3.1$

$25.1 \pm 4.1$

$22.9 \pm 3.2$

$25.1 \pm 3.4$

$5.4 \pm 1.3$

$14.5 \pm 1.6$

$5.5 \pm 1.4$

Table 2 - Chemical composition of the as-deposited powders for different voltages and lanthanum concentrations.

A SEM investigation is carried out in order to study the morphological behavior of the MgLa deposited powders. Figure 2 shows the SEM pictures of the samples for different voltages as function of the La concentration. Two kind of parts could be clearly distinguished; the dark and the bright ones. The dark aggregates are attributed to magnesium phase $[27,28]$ and the 
bright ones are assigned to lanthanum [29]. The distribution of the Mg and La elements is not uniform due to the heterogeneous chemical structures of the powders. Figure 2 shows also when the voltage increases, the growth of the formed seeds going to increase and their number tends to reduce for each La weight percentage. Indeed, the increase of current density (i.e. decrease of voltage in this study) leads to a remoteness from the equilibrium voltage according to Tafel's law. This leads an increase in the polarization and therefore an increasing in the number of seeds. For each voltage value, the increase of La weight percentage increases the concentration of the electroactive ions leading to a decrease in the germination speed. Consequently, the growth of the formed seeds tends to increase allowing the aggregation of large seeds for higher content of La.

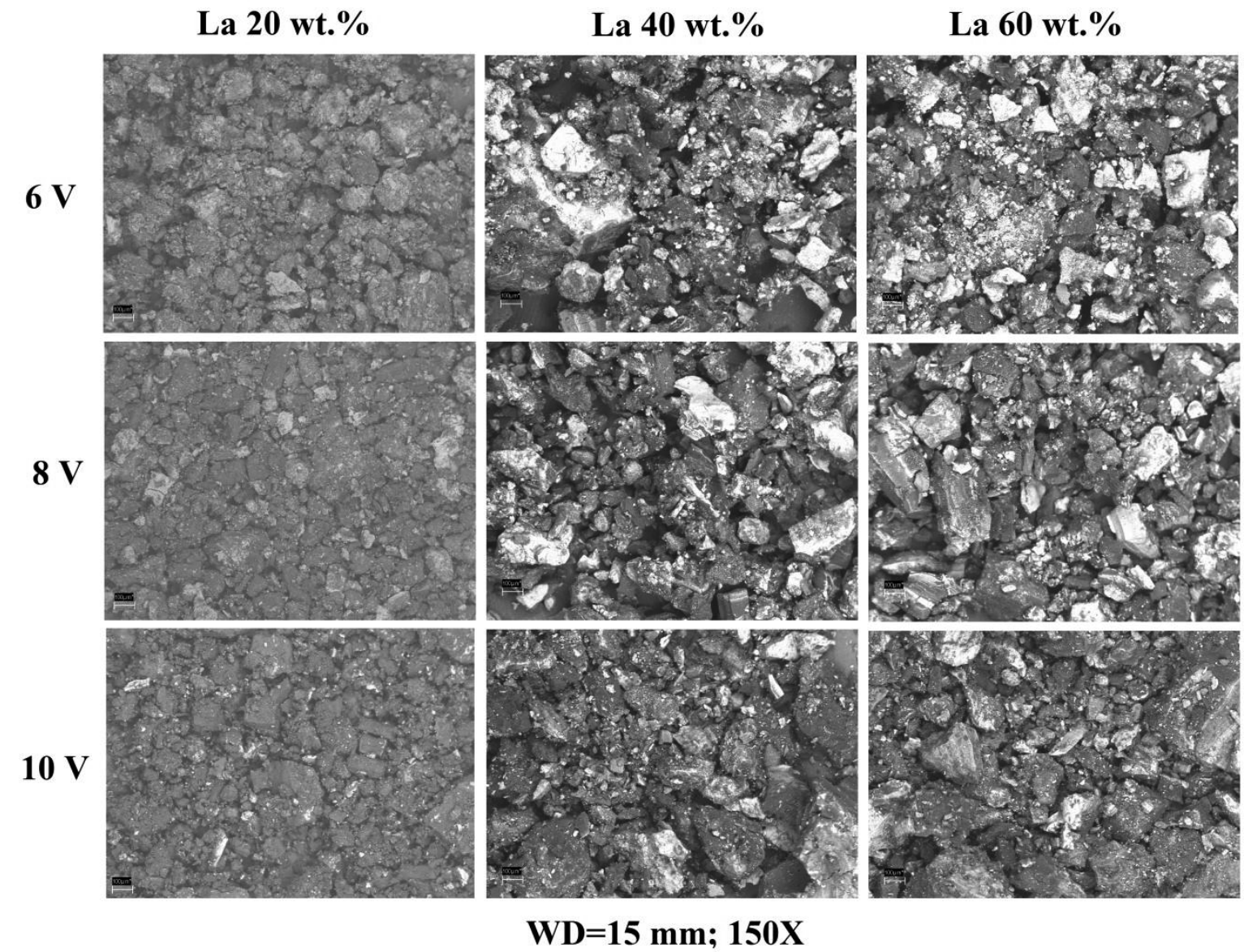

Figure 2 - SEM images of the as-deposited powders for different voltages and lanthanum concentrations. 


\section{$3.2 X$-ray diffraction analyses of the as-prepared powders}

XRD diffractograms of the as-deposited layers were measured and are given in Figure 3. According to the standard data JCPDS, the obtained deposits can be readily indexed to two phases, magnesium hydroxide $\left(\mathrm{Mg}(\mathrm{OH})_{2}\right)$ and lanthanum hydroxide $\left(\mathrm{La}(\mathrm{OH})_{3}\right)$. As we can see from this Figure, peaks at diffraction angle $2 \theta$ of $18.6^{\circ}, 35.8^{\circ}, 37.9^{\circ}, 50.8^{\circ} 58.7^{\circ}$ and $62.1^{\circ}$ are associated to $\mathrm{Mg}(\mathrm{OH})_{2}$ whereas those at $2 \theta$ of $15.6^{\circ}, 27.9^{\circ}, 39.3^{\circ}, 46.8^{\circ}, 48.5^{\circ}$ and $54.9^{\circ}$ are attributed to $\mathrm{La}(\mathrm{OH})_{3}$. For La percentages of 20 and 40 wt.\%, it can be observed that all peak intensities of $\mathrm{La}(\mathrm{OH})_{3}$ phase decrease with increasing voltage to reach a minimum at $8 \mathrm{~V}$ and then increase when the voltage increases to $10 \mathrm{~V}$. Similar tendency is observed for almost all peak intensities of $\mathrm{Mg}(\mathrm{OH})_{2}$ for La percentage of $40 \mathrm{wt}$.\%. We can also see that, for La weight percentages of 20 and $60 \%$, almost peak intensities of $\mathrm{Mg}(\mathrm{OH})_{2}$ phase increase by increasing the electrodeposition voltage. The same behavior is exhibited concerning the $\mathrm{La}(\mathrm{OH})_{3}$ phase for a La weight percentage of $60 \%$. 

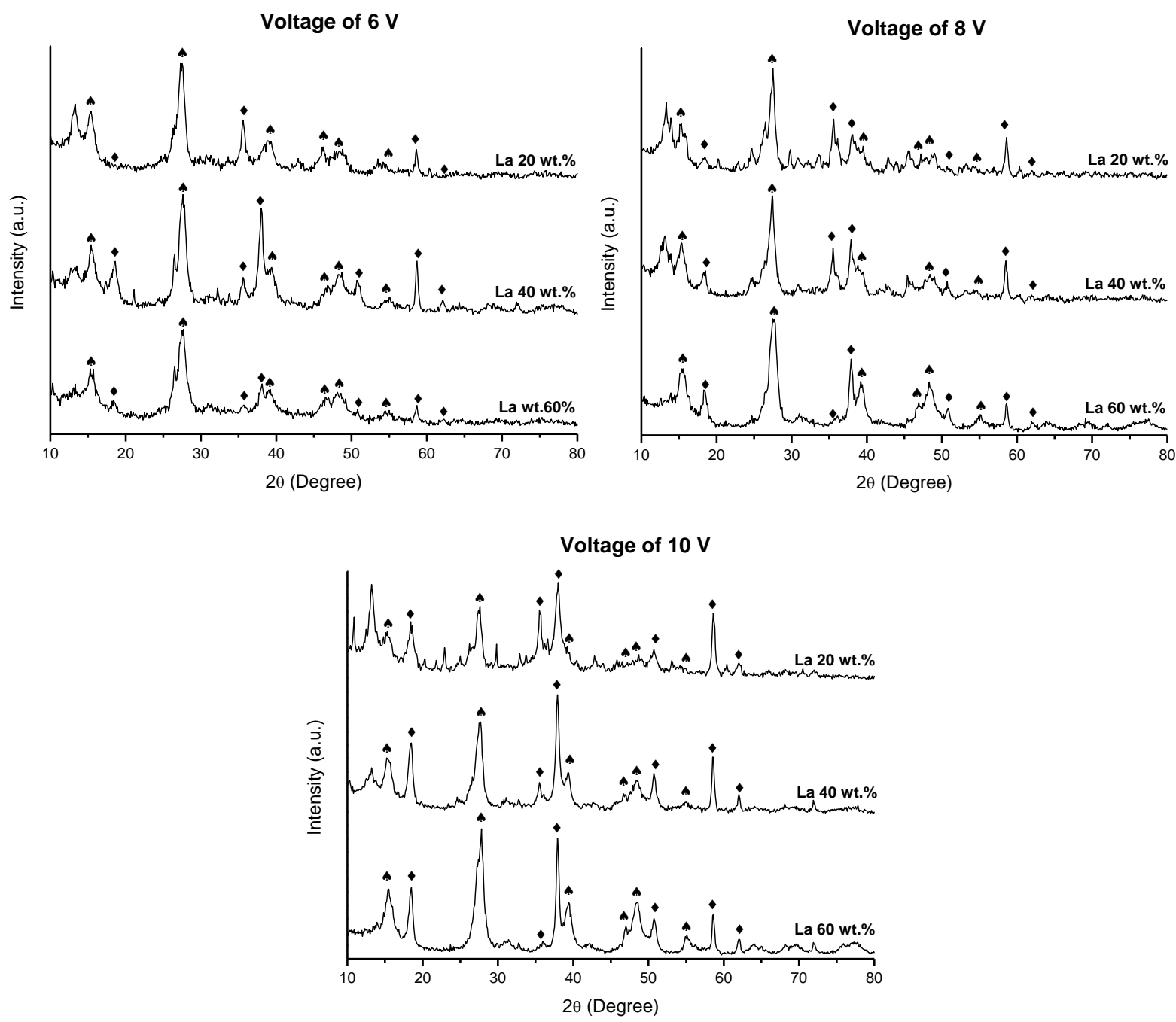

Figure 3 - X-ray diffraction patterns of samples for different voltages and lanthanum concentrations: $(\bullet) \mathrm{Mg}(\mathrm{OH})_{2} ;(\boldsymbol{\wedge}) \mathrm{La}(\mathrm{OH})_{3}$

\subsection{FTIR spectroscopy analyses of the as-deposited layers}

In addition to the X-ray diffraction analyses, the FTIR spectroscopy study is primary for the structural confirmation of the as-prepared powders. Figure 4 shows the FTIR transition spectra of the as-deposited Mg-La powders in the range of $4000-500 \mathrm{~cm}^{-1}$ for the different samples. One can see from this Figure a sharp and strong peak at $3696 \mathrm{~cm}^{-1}$ which corresponds to deformation of $\mathrm{OH}$ bonds in $\mathrm{Mg}(\mathrm{OH})_{2}$ as reported by Jianjun et al. [30] and Gray-Munro and Strong [31]. The band centred on $3606 \mathrm{~cm}^{-1}$ is assigned for stretching mode of $\mathrm{OH}^{-}$in lanthanum hydroxide $[32,33]$. The bands at $3455 \mathrm{~cm}^{-1}$ and $1640 \mathrm{~cm}^{-1}$ are 
attributed to the hydroxyl groups in water [32, 34]. The two others distinct bands at about $1434 \mathrm{~cm}^{-1}$ and $1048 \mathrm{~cm}^{-1}$ can be associated to asymmetric stretching vibrations of the carbonate group, which originate from the reaction of the as-deposited powders with $\mathrm{CO}_{2}$ from air during the FTIR spectroscopy analysis [30, 32, 34]. Regarding the concentration effect at $6 \mathrm{~V}$ on the different detected bands, one should note that there is an increase in transmittance values with increasing La weight percentage for the bands of $\operatorname{Mg}(\mathrm{OH})_{2}$, $\mathrm{La}(\mathrm{OH})_{3}, \mathrm{H}_{2} \mathrm{O}$ and $\mathrm{CO}_{2}$. Similar tendencies have been also remarked for bands of the water and the $\mathrm{CO}_{3}{ }^{2-}$ group at $10 \mathrm{~V}$. Non-monotonic behaviors at $8 \mathrm{~V}$, characterized by a decreasing phase in the La concentration range of $20-40 \mathrm{wt} . \%$ and an increasing one in $40-60 \mathrm{wt} . \%$, have been observed for the all detected bands. For the $\mathrm{Mg}(\mathrm{OH})_{2}$ and $\mathrm{La}(\mathrm{OH})_{3}$ phases, it can be seen also that the transmittance values increase in the La amount range of $20-40 \mathrm{wt} . \%$ and decrease in $40-60$ wt.\% at an electrodepositing voltage of $10 \mathrm{~V}$. 

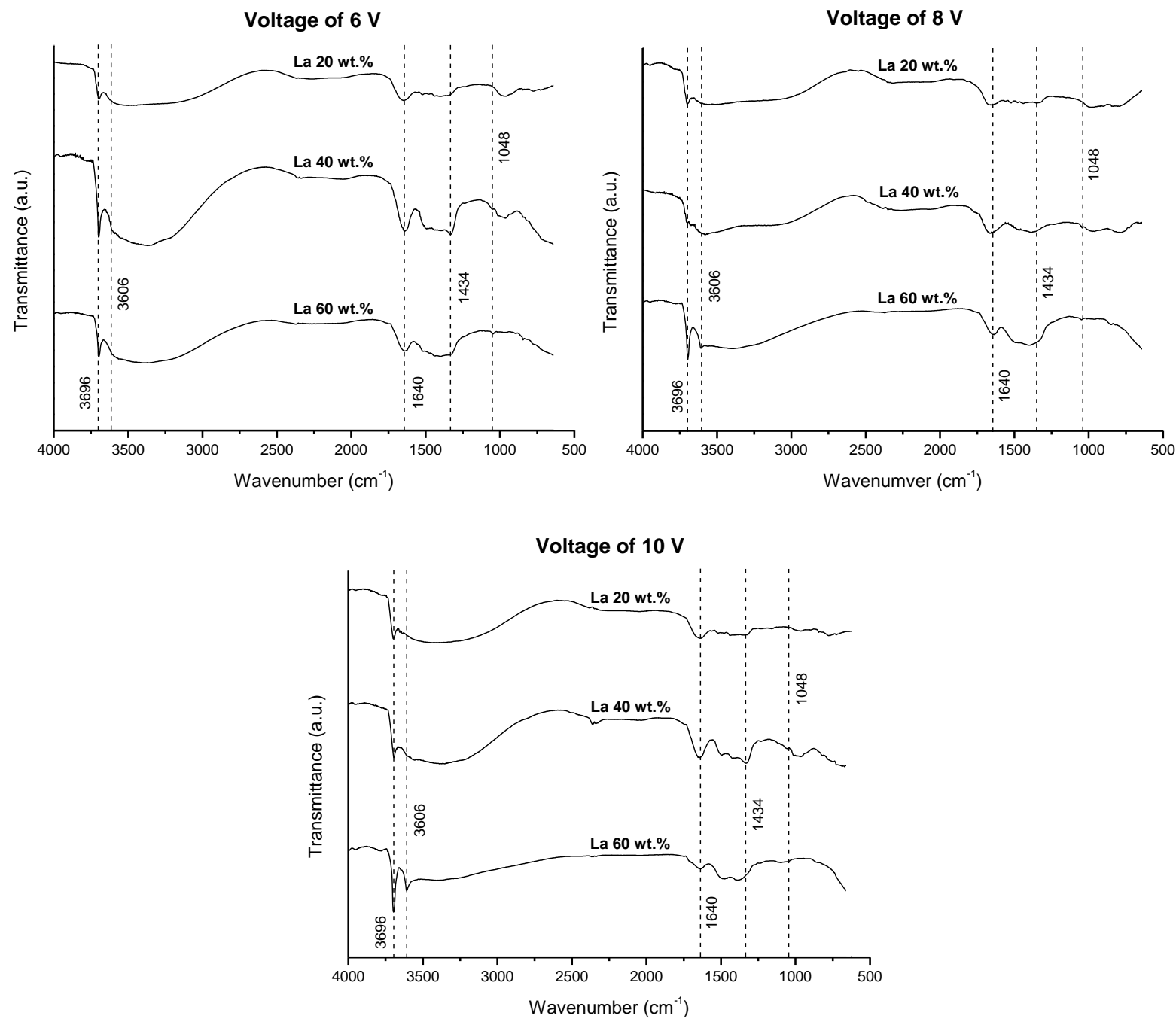

Figure 4 - FTIR transition spectra of samples for different voltages and lanthanum concentrations.

\subsection{Quantification of processing parameters effects}

The data of EDS analyses have been then post-processed to evaluate the $\mathrm{Mg}(\mathrm{OH})_{2}$ content according to the design of experiments. The two processing parameters (La weight percentage and voltage) are considered with their three levels noted " -1 " for low level, " 0 " for center level and " +1 " for high level (with the values given by Table 1). Table 3 summarize the number of experiment, the values taken by the La weight percentage (A), the voltage (B), 
their squares $\left(\mathrm{A}^{2}, \mathrm{~B}^{2}\right)$ and their interaction $\mathrm{AB}$ as well as the $\mathrm{Mg}(\mathrm{OH})_{2}$ amount. The values taken by $\mathrm{AB}$ are the scalar products results between those of $\mathrm{A}$ and $\mathrm{B}$.

Computer generated non-linear quadratic models are given as:

$$
\begin{aligned}
\operatorname{Mg}(\mathrm{OH})_{2}[\text { at. } \%] & =0.4583+0.0012 X_{\mathrm{A}}+0.0214 X_{B} \\
& +0.0127 X_{\mathrm{A}}^{2}-0.0244 X_{\mathrm{B}}^{2}-0.0171 X_{\mathrm{A}} \cdot X_{\mathrm{B}}
\end{aligned}
$$

where $X_{\mathrm{A}}$ and $X_{\mathrm{B}}$ are respectively the dimensionless values of the La weight percentage and the voltage:

$$
X_{\mathrm{A}}=\frac{\mathrm{A}-\mathrm{A}_{\mathrm{c}}}{\Delta \mathrm{A}} \text { and } X_{\mathrm{B}}=\frac{\mathrm{B}-\mathrm{B}_{\mathrm{c}}}{\Delta \mathrm{B}}
$$

with $A_{c}=40 \%$ and $B_{c}=8 \mathrm{~V}$ are the real values of the independent variables at the center point and $\Delta \mathrm{A}=20 \%$ and $\Delta \mathrm{B}=2 \mathrm{~V}$ are respectively the step changes of variables $\mathrm{A}$ and $\mathrm{B}$. The goodness-of-fit of the relation (1) is estimated with the coefficient of determination, and its value is $R^{2}=0.8981$.

It appears that the voltage is the most influencing parameter with an effect of 0.0214 . Indeed, the effect of voltage is about 18 times more important than the one of the La weight percentage. Moreover, it is only about 1.25 times more significant than the interaction parameter $\mathrm{AB}$ leading to an effect higher than the one of the La weight percentage. The square of factor $\mathrm{A}$ has a positive impact, while $\mathrm{B}^{2}$ has a negative impact on the response. Let us notice also that the quadratic terms have the same order of magnitude of the parameters B and $\mathrm{AB}$. Similar tendency concerning parameter influences ranking has been observed by Trindade et al. [35]. 


\begin{tabular}{|c|c|c|c|c|c|c|}
\hline \multirow{2}{*}{$\begin{array}{c}\text { Test } \\
\text { number }\end{array}$} & & & \multicolumn{2}{|c|}{ Squares of factors } & Interaction & $\begin{array}{c}\text { Amount of } \mathrm{Mg}(\mathrm{OH})_{2} \\
\text { [atomic \%] }\end{array}$ \\
\hline & $\mathbf{X}_{\mathbf{A}}$ & $\mathbf{X}_{\mathbf{B}}$ & $\mathbf{X}_{\mathbf{A}} \cdot \mathbf{X}_{\mathbf{A}}$ & $\mathbf{X}_{\mathbf{B}} \cdot \mathbf{X}_{\mathbf{B}}$ & $\mathbf{X}_{\mathrm{A}} \cdot \mathbf{X}_{\mathbf{B}}$ & \\
\hline 1 & 1 & 1 & 1 & 1 & 1 & $45.61 \%$ \\
\hline 2 & 1 & 0 & 1 & 0 & 0 & $47.61 \%$ \\
\hline 3 & 1 & -1 & 1 & 1 & -1 & $43.59 \%$ \\
\hline 4 & 0 & 1 & 0 & 1 & 0 & $44.86 \%$ \\
\hline 5 & 0 & 0 & 0 & 0 & 0 & $44.86 \%$ \\
\hline 6 & 0 & -1 & 0 & 1 & 0 & $42.89 \%$ \\
\hline 7 & -1 & 1 & 1 & 1 & -1 & $48.68 \%$ \\
\hline 8 & -1 & 0 & 1 & 0 & 0 & $47.59 \%$ \\
\hline 9 & -1 & -1 & 1 & 1 & 1 & $39.81 \%$ \\
\hline
\end{tabular}

Table 3 - Design of experiments matrix with $\mathrm{Mg}(\mathrm{OH})_{2}$ content results.

\section{Conclusion}

The present study deals with the synthesis of magnesium-lanthanum powders thanks to an electrodeposition process at ambient temperature. The effects of voltage and La amount on the elemental composition, the morphological characteristics and the identified phases as well as the transmittance bands have been investigated. The deposited powders are composed of $\mathrm{Mg}(\mathrm{OH})_{2}$ and $\mathrm{La}(\mathrm{OH})_{3}$ phases. A design of experiments was made in order to study the effects of the two processing parameters. In a future stage of this work, other parameters such as electrolyte temperature, $\mathrm{pH}$ and cathode nature will be treated to determine the most influential ones by using a complete design of experiments. The effect of a pressurized environment on the preparation of samples as well as a quantitative determination of the content of each powder will be also investigated. As a final point, this study is a preliminary 
work to figure out the usability of the obtained samples as potential materials for hydrogen storage.

\section{References}

[1] A.A. Zaldívar-Cadena, I. Díaz-Peña, J.G. Cabañas-Moreno, Dispersion of niquel on the microstructure in magnesium based alloys for hydrogen storage, Journal of Magnesium and Alloys, Vol. 1, 2013, pp. 292-296.

[2] V.M. Skripnyuk, E. Rabkin, Y. Estrin, R. Lapovok, Improving hydrogen storage properties of magnesium based alloys by equal channel angular pressing, International Journal of Hydrogen Energy, Vol. 34, 2009, pp.6320-6324.

[3] N. Cui, P. He, J.L. Luo, Synthesis and characterization of nanocrystalline magnesiumbased hydrogen storage alloy electrode materials, Electrochimica Acta, Vol. 44, 1999, pp. 3549-3558.

[4] S.S. Makridis, E.I. Gkanas, G. Panagakos, E.S. Kikkinides, A.K. Stubos, P. Wagener, S. Barcikowski, Polymer-stable magnesium nanocomposites prepared by laser ablation for efficient hydrogen storage, International Journal of Hydrogen Energy, Vol. 38, 2013, pp.11530-11535.

[5] J.C. Crivello, T. Nobuki, T. Kuji, Improvement of $\mathrm{Mg}-\mathrm{Al}$ alloys for hydrogen storage applications, International Journal of Hydrogen Energy, Vol. 34, 2009, pp. 1937-1943.

[6] C. Pohlmann, L. Röntzsch, S. Kalinichenka, T. Hutsch, B. Kieback, Magnesium alloy-graphite composites with tailored heat conduction properties for hydrogen storage applications, International Journal of Hydrogen Energy, Vol. 35, 2010, pp. 12829-12836. 
[7] Q.S. Zhao, Y.N. NuLi, Y.S. Guo, J. Yang, J.L. Wang, Reversibility of electrochemical magnesium deposition from tetrahydrofuran solutions containing pyrrolidinyl magnesium halide, Electrochimica Acta, Vol. 56, 2011, pp. 6530-6535.

[8] B.L. Mordike, T. Ebert, Magnesium: Properties — applications — potential, Materials Science and Engineering: A, Vol. 302, 2001, pp. 37-45.

[9] F. Rosalbino, E. Angelini, S. De Negri, A. Saccone, S. Delfino, Electrochemical behaviour assessment of novel Mg-rich $\mathrm{Mg}-\mathrm{Al}-\mathrm{RE}$ alloys (RE=Ce, $\mathrm{Er}$ ), Intermetallics, Vol. 14, 2006, pp.1487-1492.

[10] M. Bornapour, M. Celikin, M. Cerruti, M. Pekguleryuz, Magnesium implant alloy with low levels of strontium and calcium: The third element effect and phase selection improve bio-corrosion resistance and mechanical performance, Materials Science and Engineering: C, Vol. 35, 2014, pp. 267-282.

[11] C.A. Grillo, F. Alvarez, M.A. Fernández Lorenzo de Mele, Cellular response to rare earth mixtures (La and $\mathrm{Gd}$ ) as components of degradable $\mathrm{Mg}$ alloys for medical applications, Colloids and Surfaces B: Biointerfaces, Vol. 117, pp. 312-321, 2014.

[12] W. Liu, F. Cao, L. Chang, Z. Zhang, J. Zhang, Effect of rare earth element Ce and La on corrosion behavior of AM60 magnesium alloy, Corrosion Science, Vol. 51, pp. 1334-1343, 2009.

[13] H. Chu, Y. Zhang, L. Sun, S. Qiu, F. Xu, H. Yuan, Q. Wang, C. Dong, Structure, morphology and hydrogen storage properties of composites prepared by ball milling $\mathrm{Ti}_{0.9} \mathrm{Zr}_{0.2} \mathrm{Mn}_{1.5} \mathrm{Cr}_{0.3} \mathrm{~V}_{0.3}$ with La-Mg-based alloy, International Journal of Hydrogen Energy, Vol. 32, pp. 3363-3369, 2007.

[14] S. Yang, F. Yang, C. Liao, M. Li, X. Wang, Electrodeposition of magnesium-yttrium alloys by molten salt electrolysis, Journal of Rare Earths, Vol. 28, 2010, pp. 385-388. 
[15] Z. Abdel Hamid, M.T. Abou El-khair, H.B. Hassan, Synthesis and protection of AM50 magnesium alloy and its composites using environmentally pretreatment electrolyte, Surface and Coatings Technology, Vol. 206, 2011, pp. 1041-1050.

[16] M. Parco, L. Zhao, J. Zwick, K. Bobzin, E. Lugscheider, Investigation of HVOF spraying on magnesium alloys, Surface and Coatings Technology, Vol. 201, 2006, pp. 3269-3274.

[17] F. Liu, W. Liang, X. Li, X. Zhao, Y. Zhang, H. Wang, Improvement of corrosion resistance of pure magnesium via vacuum pack treatment, Journal of Alloys and Compounds, Vol. 461, 2008, pp. 399-403.

[18] S. Ignat, P. Sallamand, D. Grevey, M. Lambertin, Magnesium alloys laser (Nd:YAG) cladding and alloying with side injection of aluminium powder, Applied Surface Science, Vol. 225, 2004, pp. 124-134.

[19] Ch. Christoglou, N. Voudouris, G.N. Angelopoulos, M. Pant, W. Dahl, Deposition of aluminium on magnesium by a CVD process, Surface and Coatings Technology, Vol. 184, 2004, pp. 149-155.

[20] Y. NuLi, J. Yang, P. Wang, Electrodeposition of magnesium film from BMIMBF 4 ionic liquid, Applied Surface Science, Vol. 252, 2006, pp. 8086-8090.

[21] K.R. Liu, Q. Liu, Q. Han, G.F. Tu, Electrodeposition of Al on AZ31 magnesium alloy in TMPAC-AlCl 3 ionic liquids, Transactions of Nonferrous Metals Society of China, Vol. 21, 2011, pp. 2104-2110.

[22] S. Wang, X. Guo, H. Yang, J. Dai, R. Zhu, J. Gong, L. Peng, W. Ding, et al., Electrodeposition mechanism and characterization of $\mathrm{Ni}-\mathrm{Cu}$ alloy coatings from a eutectic-based ionic liquid, Applied Surface Science, Vol. 288, 2014, pp. 530-536. 
[23] A. Bakkar, V. Neubert, Electrodeposition onto magnesium in air and water stable ionic liquids: From corrosion to successful plating, Electrochemistry Communications, Vol. 9, 2007, pp. 2428-2435.

[24] N. Gascoin, P. Gillard, G. Baudry, Characterisation of oxidised aluminium powder: Validation of a new anodic oxidation bench, Journal of Hazardous Materials, Vol. 171, pp. 348-357, 2009.

[25] A.H. Khan, J.Q. Shang, R. Alam, Ultrasound-assisted extraction for total sulphur measurement in mine tailings, Journal of Hazardous Materials, Vol. 235-236, 2012, pp. 376-383.

[26] J. Beltrán-Heredia, J. Sánchez-Martín, M.A. Dávila-Acedo, Optimization of the synthesis of a new coagulant from a tannin extract, Journal of Hazardous Materials, Vol. 186, 2011, pp. 1704-1712.

[27] H. Tang, Y.D. Yan, M.L. Zhang, X. Li, W. Han, Y. Xue, Z.J. Zhang, H. He, Fabrication of Mg-Pr and Mg-Li-Pr alloys by electrochemicalco-reduction from their molten chlorides, Electrochimica Acta, Vol. 107, 2013, pp. 209-215.

[28] S.Q. Wei, M.L Zhang, W. Han, Y.D. Yan, M. Zhang, B. Zhang, Electrochemical codeposition of Mg-Li-Gd alloys from LiCl-KCl- $\mathrm{MgCl}_{2}-\mathrm{Gd}_{2} \mathrm{O}_{3}$ melts, Transactions of Nonferrous Metals Society of China, Vol. 21, 2011, pp. 825-829.

[29] J. Gröbner, M. Hampl, R. Schmid-Fetzer, M.A. Easton, S. Zhu, M.A. Gibson, J.F. Nie, Phase analysis of Mg-La-Nd and Mg-La-Ce alloys, Intermetallics, Vol. 28, 2012, pp. 92-101.

[30] L. Jianjun, Y. Xiaoyan, C. Jia, L. Xiaowei, F. Chengxing, C. Youfa, The gemmological properties and infrared spectra of brucite, an imitation of nephrite and Shoushan stone, Journal of Gemmology, Vol. 32, 2010,pp. 67-73. 
[31] J.E. Gray-Munro, M. Strong, A study on the interfacial chemistry of magnesium hydroxide surfaces in aqueous phosphate solutions: Influence of $\mathrm{Ca}^{2+}, \mathrm{Cl}^{-}$and protein, Journal of Colloid and Interface Science, Vol. 393, 2013, pp. 421-428.

[32] M. Aghazadeh, A.N. Golikand, M. Ghaemi, T. Yousefi, A novel lanthanum hydroxide nanostructure prepared by cathodic electrodeposition, Materials Letters, Vol. 65, 2011, pp. 1466-1468.

[33] M. Salavati-Niasari, G. Hosseinzadeh, F. Davar, Synthesis of lanthanum hydroxide and lanthanum oxide nanoparticles by sonochemical method, Journal of Alloys and Compounds, Vol. 509, 2011, pp. 4098-4103.

[34] F. Khosrow-pour, M. Aghazadeh, S. Dalvand, B. Sabour, Large scale and uniform $\mathrm{La}(\mathrm{OH})_{3}$ nanorods prepared by template-free pulsed electrodeposition method, Materials Letters, Vol. 104, 2013, pp. 61-63.

[35] J.M. Trindade, L.C. Martiniano, V.R.A. Gonçalves, A.G. Souza, A.L.B. Marques, G.L. Baugis, T.C.O. Fonseca, C. Song, J. Zhang, E.P. Marques, Anodic stripping voltammetry coupled with design of experiments for simultaneous determination of $\mathrm{Zn}^{+2}, \mathrm{Cu}^{+2}, \mathrm{~Pb}^{+2}$, and $\mathrm{Cd}^{+2}$ in gasoline, Fuel, Vol. 91, 2012, pp. 26-32. 